\author{
$14^{\text {th }}$ Symposium on Nutri Indonesia \\ in conjunction with \\ $6^{\text {th }}$ International Nutrition Symposium \\ July 27-28, 2019 | Jakarta, Indonesia
}

\title{
ABSTRACT
}

\section{Correlation Between Docosahexaenoic Acid Intake and It's Content in Breast Milk of Lactating Mothers in Jakarta}

\author{
Raphael Kosasih, ${ }^{1}$ Ninik Mudjihartini, ${ }^{2}$ Saptawati Bardosono ${ }^{1}$ \\ 1. Department of Nutrition, Faculty of Medicine, Universitas Indonesia, Cipto Mangunkusumo Hospital, Jakarta \\ 2. Department of Biochemistry and Molecular Biology, Faculty of Medicine, Universitas Indonesia
}

\author{
Link to DOI: \\ 10.25220/WNJ.V03.i1.0005 \\ Journal Website:
}

www.worldnutrijournal.org

Objective: Docosahexaenoic acid (DHA) is the predominant structural fatty acid in the brain and one of the most important nutrient for cognitive development in early life. During early life, there is very limited metabolic capability to convert omega-3 fatty acids to DHA. Therefore, newborn intake of DHA completely depends on preformed DHA in mother's breast milk. This study aims to determine DHA intake among lactating mothers and their association with breast milk's DHA.

Methods: This cross-sectional study was conducted in Grogol Petamburan and Cilincing Public Health Centre in Jakarta. Eighty healthy lactating mothers aged 20-35 years old in 1-6 months postpartum was taken using consecutive sampling method. Mother's DHA intake was assessed with a semi quantitative food frequency questionnaire. Post-feed breast milk specimens were collected in the morning, transported with cool boxes, and stored in the laboratory at $-70^{\circ} \mathrm{C}$ before the analyses. Breast milk DHA content was analyzed using Gas Chromatography with Mass Spectrometry. Descriptive analyses and Spearman rho test was used with a $95 \%$ confidence level.

Result: This study showed the median of subjects' DHA intake was 158.5(13.9-719.7) $\mathrm{mg} /$ day, i.e. $67.5 \%$ of the subjects was below Food and Agriculture Organization (FAO) recommendation (200 mg/day). The median of breast milk DHA was 51.7(19-184.7) mg/day, only $42.5 \%$ of the subjects had breast milk DHA to meet the minimal requirement of their infant based on FAO recommendation $(0.1 \%$ of total energy requirement). There was a moderate correlation between subject DHA intake with breast milk's DHA content $(r=0.478$, $\mathrm{p}<0.001)$.

Conclusion: More than half of the subjects had DHA intake below FAO recommendation. Our finding showed a positive moderate correlation between DHA intake and breast milk DHA among lactating mothers.

Keywords: docosahexaenoic acid, DHA, breast milk, lactating mothers

\author{
Corresponding author: \\ Raphael Kosasih \\ Jl. Kramat Sentiong Gang Mesjid No. F47, Senen, Central Jakarta, Indonesia, 10450 \\ E-mail address: raphaelkosasih@gmail.com
}

